\title{
К ВОПРОСУ О СОДЕРЖАНИИ ПРАВООТНОШЕНИЯ
}

\begin{abstract}
Аннотация: Одна из проблем общей теории права - содержание правоотношения. В отечественной юриспруденции методологические подходы исследователей идентичны в признании единства формы и содержания при решении данной научно-теоретической задачи. Однако последовательное развитие концепта нераздельного единства фактического материального содержания и юридической формы приостановилось вследствие доминирования формально-юридической методологии, сложившейся в середине ХХ века усилиями представителей ленинградской юридической школы, уральской и саратовской научной школы права. Материально-правовой подход проявили московские учёные-правоведы. Анализ ряда источников позволяет увидеть коллизионность традиционных тезисов и некоторые пробелы в научной аргументации взглядов на содержание правоотношения. В частности совокупность взаимных прав и обязанностей субъектов правоотношения представляет собой условную, логико-юридическую и неосуществлённую взаимную связь, в которой выражена публичная воля на должное поведение в общественных отношениях. Однако она рассматривается как содержание правоотношения. Логика философско-правовых рассуждений приводит нас к выводу о том, что в этом случае ирреальное признаётся тождественным реальному, идеальное подменяет собой материальное в общественной жизни. Юридическая действительность также богата примерами, не вписывающимися в абрисы надстроечной модели правоотношения. Автор полагает уместной постановку вопроса о дополнительном исследовании предпосылок правоотношения, а также считает, ито правоотношение характеризуется следующим содержанием: совокупность взаимообусловленных актов волевого правового поведения участников; осуществлённое или защищённое право как результат направленного поведения в правоотношениях, соответственно, пассивного и активного типа. Без целевой компоненты содержание правоотношения не обретает смысловой завершённости. Рассмотрение данной проблемы приводит автора к убеждению в необходимости ревизии теории правоотношения на основе незаслуженно забытых и новых достижений юридической науки. При работе над материалом использованы методы содержательно-правового анализа и синтеза, теоретической интерпретации и метод диалектической логики. Научная новизна состоит в критической оценке и развитии взглядов на структуру правоотношения на основе конфликтующих положений формально-юридического и материально-правового подходов, выработке авторских обоснований структуры и состава элементов правоотношения (юридическая форма, материально-правовое содержание, субъекты, предмет и объект правоотношения), в том числе и содержания правоотношения.

Ключевые слова: Защмщённое право, общая теория права, общественное отношение, предпосылки правоотношения, реализованное право, содержание правоотношения, права и обязанности, теория правоотношения, фрактическое содержание правоотношения, юридическая форма.
\end{abstract}

$\mathrm{H}$ аучная юридическая публицистика содержит изложение различных теоретико-правовых взглядов на содержание правоотношения, которое исследовалось правоведами не только в рамках общей теории права, но и применительно к отраслевым правоотношениям. Рассматривая вопросы общей теории права, С.С. Алексеев подчёркивает, что согласно разделяемому большинством учёных взгляду оно «характеризуется единством формы и содержания» ${ }^{1}$.

1 См.: Алексеев С.С. Общая теория права: учеб. - 2-е изд., перераб. и доп. - М.: ТК Велби, Изд-во Проспект, 2008. 576 c. C. 335. 
Соглашаясь с данным утверждением, заметим, что логика рассуждений требует раскрытия вопросов о форме и содержании правоотношения.

В работах С.C. Алексеева мы находим тезисы о содержании правоотношения, но не обнаруживаем ясной позиции по вопросу о его форме. Кроме того, С.С. Алексеев многократно используется термин «связь» (особая общественная, между лицами, индивидуализированная) ${ }^{2}$, но вкладывает в это понятие смысл занимаемого «по отношению друг к другу определённого положения (состояния, позиции), что, с одной стороны характеризует исключительно правовую соотносимость статутных прав и обязанностей субъектов права, а с другой создаёт в целом формально-статическую картину правоотношения.

Полагаем, что приведенные характеристики связи не идентичны правовой связи, которую имеет в виду автор, размышляя об этой черте правоотношения и выводя в название параграфа термин «правовая связь», и вопрос о «связи» и её соотношении с содержанием правоотношения остаётся открытым. Это обстоятельство побуждает нас поделиться следующими соображениями.

Перечисляя специфические признаки правоотношения автор обращает внимание на то, что эта «связь» возникает между лицами на основе норм права и через их субъективные права и обязанности, гарантируется государством и имеет индивидуализированно-определённый характер 3 .

В этом мы видим её правовой характер, но, рассматривая конкретное правоотношение нельзя отстраняться от его материально-правовой стороны, усматривая взаимосвязи только в определённом соотношении субъективных прав и обязанностей ${ }^{4}$. Хотя бы потому, что они, во-первых, выражены в норме права, те есть условно-идеальны. Во-вторых, они не характеризуют фактически сложившуюся правовую ситуацию (правоотношение), а очерчивают идеальную модель должного поведения участвующих в правоотношении сторон. В-третьих, они должны осознаваться каждым субъектом права, но могут быть неведомы им и тогда мотивы поведения оказываются внеправовыми, определяемыми иными группами социальных регуляторов

\footnotetext{
2 См.: Алексеев С.С. Указ. соч. С. 328, 330, 338 и др.

3 Там же. С. 328-330.

4 См.: Борисов А.М. О проблеме трактовки категории «объект» в правоведении // Актуальные проблемы российского права. - 2014. - 3. - С. 323 - 329. DOI: 10.7256/19941471.2014.3.9396.
}

или психоэмоциональными переживаниями лица. В-четвёртых, рассматривая права и обязанности отвлечённо от фактических явлений, событий и деяний, мы должны констатировать следующее - в этом случае они остаются неосуществлёнными. Следуя этой концепции, мы теряем основания говорить о правоотношении и ведём речь об идеально-ожидаемой модели поведения в правоотношении.

Таким образом, совокупность взаимных прав и обязанностей субъектов правоотношения представляет собой условную, логико-юридическую и неосуществлённую (фактически мы оперируем юридическими категориями, описывающими нереализованные права и обязанности) взаимную связь, в которой выражена публичная воля на должное поведение в общественных отношениях. Также уместно говорить о взаимосвязи соответствующих норм права, которая имеет свои разновидности: взаимосвязь норм, закрепляющих статутные права и обязанности одного лица в рамках конкретного правоотношения; взаимосвязь норм, закрепляющих соотносимые статутные права и обязанности двух сторон правоотношения (праву одного лица соответствуют обязанности другого и наоборот, обязанностям первого лица соответствуют права второго); аналогичная взаимосвязь норм при условии участия в правоотношении третьих лиц.

В этом смысле статутные права и обязанности несут черты элемента юридической формы особого общественного отношения, каким представляется правоотношение, и термин «юридическое содержание» здесь представляется некорректным. Употребление данного термина вполне допустимо при анализе правовой формы, которую также может характеризовать определённое содержание (содержание правовой формы).

У С.C. Алексеева выражена позиция, согласно которой место правоотношения как «формы реальных отношений» определяется в «юридической надстройке» 5 .

Коллизионность данного тезиса состоит в том, что возникает задача определения сущностного содержания юридической надстройки общественной жизни, а логика её решения требует признания одного из двух вариантов: либо правоотношение есть форма общественного отношения либо это надстроенное над реальным общественным отношением отношение.

Первый вариант представляет материальноправовое отношение, а второй, построенный на

Там же. С. 335. 
позиции большинства правоведов, - идеальноправовое отношение, оторванное от своего материального содержания.

В рамках последнего варианта принцип единства формы и содержания только декларируется. В доказательство этого тезиса заметим, что выделяя материальное содержание (поведение субъектов) и юридическое содержания (субъективные права и обязанности) ${ }^{6}$, автор тем самым структурирует содержание правоотношения, но, по сути, сводит его к единственному компоненту - совокупности прав и обязанностей в контексте должного поведения.

Юридическая форма общественного отношения как элемент структуры правоотношения является надстроечной категорией долженствования, и рассматривая единство формы и содержания как определённую условность, следует отнести составляющие правового статуса субъекта правоотношения к содержанию юридической формы такового.

Фактическая реализация прав и обязанностей, выражаемая в поведении и образующая материально-поведенческую связь лиц и, по мнению другой части правоведов, собственно материальноправовое содержание правоотношения, остаётся «за кулисами» сцены правовой жизни. В результате на «сцене» юридической действительности мы имеем застывшую группу «актёров», а правоотношение предстаёт перед нами в чрезмерно упрощённом виде, идеально-юридической категорией, «воспарившей» над бренной действительностью.

Приведём высказывание Р.О. Халфиной: «правоотношение берётся всегда как элемент реальной жизни» ${ }^{7}$. Именно с этих позиций выстраивает P.O. Халфина реалистическую концепцию формы и содержания правоотношения.

Критика «модельной» концепции правоотношения у С.С. Алексеева сочетается с представлением собственной «модельной» неподвижной юридической конструкции ${ }^{8}$, надстроенной над материально-правовыми реалиями, которое, всё же, получает некоторое диалектико-материалистическое уточнение: «права и обязанности в правоотношении как динамическом явлении могут находиться в развитии».

\footnotetext{
6 Там же. С. 335, 343.

7 См.: Халфина Р.О. Общее учение о правоотношении. - М.: Юр. лит. - 1974. - 340 с. С. 89.

8 См.: Алексеев С.С. Указ. соч. С. 330, 338.

9 Там же. С. 330.
}

Однако в данном уточнении просматривается та же надстроечно-обособленная модель правоотношения, поскольку его динамика связывается исключительно с развитием прав и обязанностей без обращения к фактическим основаниям развития правоотношения.

В связи с этим выскажем следующее мнение. Права и обязанности субъекта права не эволюционируют сами по себе, поскольку представляют собой «застывшую форму», правовое установление для конкретного правоотношения. Первоначальное значение для их изменения, а точнее - возникновения у лица или приобретения лицом дополнительных в рамках конкретного правоотношения прав и обязанностей, при наличии общих предпосылок и условии правосубъектности, имеют специально-юридические предпосылки в виде правовых норм, определяющих содержание дополнительных прав и обязанностей, и определённого юридического факта. Причём последний будет иметь приоритетное значение для изменения конфигурации прав и обязанностей, а, следовательно, и содержания правоотношения.

Считаем важным подчеркнуть, что изменение правоотношения или возникновение нового правоотношения в результате каких-либо актов поведения или событий происходит не всегда. Например, в ответ на обращение гражданина уполномоченным лицом совершается правовое действие, которое состоит в просьбе уточнить содержание жалобы и за которым следует соответствующее действие обратившегося лица. Фрагмент правоотношения по поводу обращения граждан неизменен, но в рамках этого простейшего правоотношения участвующими лицами совершаются определённые действия - акты волевого поведения, соответствующие статутным правам и обязанностям. Другой случай: в рамках предыдущего правоотношения совершается действие (юридический акт), а его следствием оказывается определённый юридический факт, который одновременно становится предпосылкой нового правоотношения (например, обращение в суд). В частности, М.Б. Добробаб обоснованно полагает, что содержание служебно-деликтных правоотношений является производным от юридического содержания служебного правоотношения с особенностями, связанными с их отнесением к охранительным правоотношениям, но выражает традиционную точку зрения на содержание правоотношения ${ }^{10}$.

10 Добробаба М.Б. Содержательная характеристика служебно-деликтных правоотношений // Актуальные пробле- 
Таким образом, права и обязанности, соответствующие одной правовой ситуации (правоотношению) не находятся в развитии (мы не говорим о правотворчестве законодателя), поскольку они определены законодателем для тех или иных этапов развития правоотношения также, как другие права и обязанности определены для последующего правоотношения.

Корректнее было бы говорить не о развитии прав и обязанностей, а о развитии правоотношения или прекращении одного и возникновении нового правоотношения. При этом все трансформации правоотношения обусловлены юридическими фактами (событиями или деяниями).

В анализируемой позиции правоведов мы усматриваем противоречие с материалистическим взглядом, согласно которому общественные (фактические) отношения, «накрываемые» правом, становятся правовыми общественными отношениями или получают дополнительную характеристику правовых отношений (действительность в виде поведенческих актов или событий приобретает правовые черты и юридическое значение), а не разделяются на материальные (лежащие в основе) и надстроечные (чисто юридические).

Указанные обстоятельства требуют уточнения общего взгляда на правоотношение, которое не всегда прекращается вслед за новыми юридическими фактами, но всегда включает в себя определённые факты (реакции или явления, например акты поведения в наследственном отношении) правового значения или приобретающие правовое значение.

Конкретизация содержания правоотношения применительно к отраслям права осуществляется преимущественно с тех же позиций. Например, рассматривая наследственные правоотношения Н.И. Остапюк упоминает позицию А.Г. Певзнера, включившего в содержание правоотношения кроме субъективного права и соответствующей ему обязанности обоюдную связанность поведения субъектов правоотношения, но замечает, что эта позиция не получила распространения в правовой литературе ${ }^{11}$ (например, поведенческий акт одной

мы российского права. - 2013. - 11. - С. 1391 - 1403. DOI: 10.7256/1994-1471.2013.11.8937.

11 См.: Остапюк Н.И. Наследственное правоотношение: понятие и юридическое содержание // Гражданское право, 2006. № 2 (Справочная правовая система «КонсультантПлюс») (в своей работе автор приводит источник: Певзнер А.Г. Понятие гражданского правоотношения и некоторые стороны правоотношения инициирует соответствующий поведенческий акт другой стороны). Далее автор, перечисляя элементы правоотношения, принимает позицию С.С. Алексеева, определяя элементом правоотношения не содержание, а юридическое содержание, и понимая под последним права и обязанности участников.

Однако вступление в правоотношение осуществляется лицом или посредством совершения определённых актов поведения или независимо от их совершения. Например, Н.И. Остапюк отмечает, что наследственное правоотношение «возникает в тот момент, когда наследодатель «выбывает» из числа субъектов правовых отношений, и прекращается, когда их «трансформация» завершена - произошла замена субъектного состава правоотношений» ${ }^{12}$.

Очевидно, что в рамках наследственных отношений до их прекращения наследники совершают определённые действия с целью реализации своих прав или отказываются от их совершения, что также может рассматриваться как акт волевого поведения. Поэтому, усматривая аналогичные схемы в отраслевом разнообразии правоотношений, мы не можем согласиться с выделением лишь юридического содержания правоотношения в предлагаемой трактовке, тем более что в анализируемой позиции значение юридического содержания придано юридической форме.

Рассмотрим кратко эволюцию взглядов правоведов на содержание правоотношения.

Анализируя гражданско-правовые отношения, О.С. Иоффе недвусмысленно и категорично определяет субъективные права и обязанности единственным содержанием правоотношения ${ }^{13}$. Данный подход стал доминирующим в отечественном правоведении.

По мнению Ю.К. Толстого, при определении содержания правоотношения «необходимо исхо-

вопросы теории субъективных гражданских прав. Ученые записки. Вып. V. Вопросы гражданского права. М.: ВЮЗИ, 1958. C. 15-16).

Справка: Певзнер А.Г. Понятие и виды субъективных гражданских прав. Диссертация на соискание ученой степени кандидата юридических наук. М., 1961. 245 стр.

12 См.: Остапюк Н.И. Указ. соч.

13 См.: Иоффе О. С. Правоотношение по советскому гражданскому праву /О. С. Иоффе; Отв. ред. С.И. Аскназий; Ленинградский государственный университет им. А.А. Жданова. Институт экономики, философии и права. - Л.: Изд-во ЛГУ, 1949. - 143 c. URL: http://law.edu.ru/book/book. asp?bookID=13808 (дата обращения - 26.08.2013 г.). 
СОДЕРЖАНИЕ ПРАВООТНОШЕНИЯ (элементарное)

\begin{tabular}{|c|}
\hline $\begin{array}{c}\text { Субъективные права } \\
\text { участника № 1 }\end{array}$ \\
\hline $\begin{array}{c}\text { Субъективные } \\
\text { обязанности } \\
\text { участника № 1 }\end{array}$ \\
$\begin{array}{c}\text { Субъективные права } \\
\text { участника № 2 }\end{array}$ \\
оббективнынес \\
участника № 1
\end{tabular}

СОДЕРЖАНИЕ ПРАВООТНОШЕНИЯ (поведенческие)

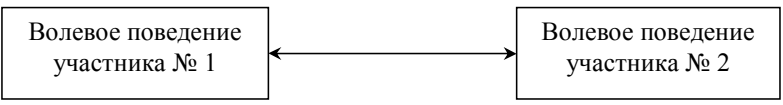

Схема 2 - Поведенческое содержание правоотношения (1959 г.)

Схема 1 - Элементарное содержание правоотношения (1959 г.)

\section{СОДЕРЖАНИЕ ПРАВООТНОШЕНИЯ}

(волевое)

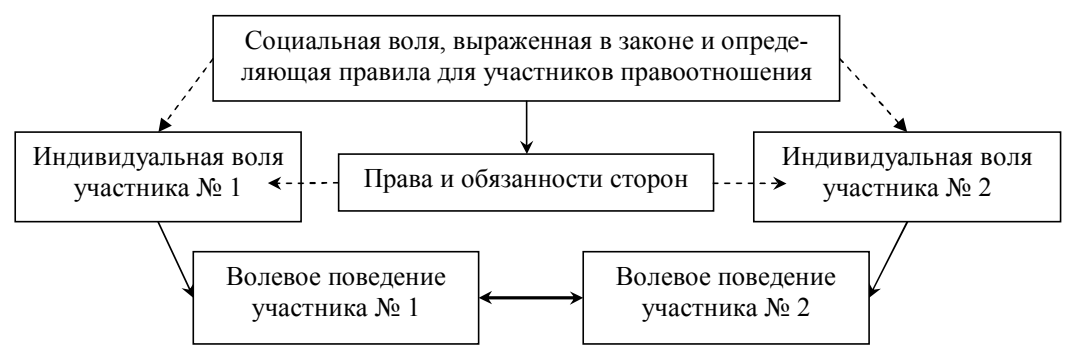

Схема 3 - Волевое содержание правоотношения (1959 г.)

дить из того, что всякое правоотношение состоит из прав и обязанностей его участников, что в правоотношении правам одних лиц соответствуют обязанности других» ${ }^{14}$. Автор уточнил, что «этот тезис служит лишь элементарной общей предпосылкой для раскрытия содержания правоотношения» ${ }^{15}$.

Таким образом, элементарное представление о содержании правоотношения состоит в том, что его суть - совокупность прав и обязанностей его сторон (схема 1).

Далее автор выражает, по сути, ещё одно мнение: «в содержание правоотношения входит лишь волевое опосредствование материального содержания экономического отношения» ${ }^{16}$, под которым мы понимаем волевое поведение (схема 2).

Затем следует ещё одно уточнение, позволяющее уяснить смысл предыдущего тезиса и вводящее элемент, обозначающий внешнюю волю, которая определяет всю совокупность правовых установлений, в том числе и основных правил общежития: «содержанием правоотношения является не просто волевое поведение его участников, а взаимодей-

14 См.: Толстой Ю.К. К теории правоотношения. - Ленинград: Изд-во Ленинградского Ун-та. - 1959. - 88 с. С. 32.

\footnotetext{
15 Там же.

16 Там же. С. 66.
}

ствие социальной воли, возведённой в закон, с индивидуальной волей субъектов правоотношения» (там же). Схема 3 учитывает эти особенности.

Фактическое, юридическое и волевое содержание усматривает в любом правоотношении Н.И. Матузов, не вполне ясно высказываясь о фактическом содержании (отношении), уже традиционно представляя юридическое содержание в виде субъективных прав и обязанностей участников правоотношения, а волевое содержание рассматривая как совокупность воли государства и воль самих субъектов ${ }^{17}$. Одновременно автор точно подмечает, что «регулируемые отношения в принципе не утрачивают своего фактического содержания», «обретая новое дополнительное свойство» ${ }^{18}$.

Последняя модель охватывает в определённой мере три выделенные нами схемы.

Вполне очевидно следующее: в первом случае (схема 1) мы имеем элемент юридической формы правоотношения (взаимообусловленные субъективные права и обязанности) ${ }^{19}$, во втором (схема 2)

17 См.: Теория государства и права: Курс лекций / Под ред. Н.И. Матузова и А.В. Малько. - 2-е изд., перераб. и доп. М.: Юристъ, 2001. - 776 с. С. 280-300.

18 Там же. С. 281.

19 Аналогична позиция В.Н. Хропанюка, который рассматривает правоотношение как форму фактического обще- 
- картину фактического волевого поведения (материально-поведенческая сторона правоотношения) участников правоотношения, а в третьем (схема 3) - отображение взаимодействия воль, включающего публичную волю, которая изначально определяет модель поведения участников правоотношения, и состав субъективных воль.

Первый вариант предлагает нам неполную модель правоотношения, в которой представлена только формально-юридическая сторона, причём представлена лишь одним её элементом (комплекс прав и обязанностей), обозначающим варианты должного и вероятного поведения (повторимся, это содержание лишь одной, формально-юридической стороны правоотношения). Во втором случае мы имеем чисто поведенческую (сугубо материальную) модель правоотношения. Третий вариант являет собой картину объективно-субъективного соотношения воль в правоотношении и, по сути, являет психологическую картину правоотношения.

Волевое взаимодействие проявляется в поведенческих ситуациях, что позволяет нам отобразить материально-правовую сторону правоотношения, а именно, конкретные правовые поступки (акты волевого поведения в рамках предписываемых правил), в основе которых лежит индивидуальная воля участников правоотношения, ограниченная волей социума, выраженной в нормах права. Однако представляется не вполне обоснованным рассматривать содержание правоотношения как комплекс исключительно волевых компонент, поскольку задаваясь этим вопросом мы переходим на уровень предпосылок правоотношения.

Действительно, чистое «взаимодействие социальной воли, возведённой в закон, с индивидуальной волей субъектов правоотношения» происходит в сознании сторон правоотношения при формировании мотивов и абриса поведения, а потому предшествует правоотношению или в его рамках приводит к корректировке позиций сторон посредством совершения определённых актов поведения. Мы не должны забывать, что в правоотношении взаимодействуют субъекты права.

Гипотезу о переходе в сферу предпосылок правоотношения при принятии волевой трактовки его содержания подтверждают следующие соображения.

ственного отношения, но полагает, что оно состоит из «взаимосвязанных прав и обязанностей». См.: Хропанюк В.Н. Теория государства и права. Учебник для высших учебных заведений / Под редакцией профессора В.Г. Стрекозова. - М. Издательство «Интерстиль», «Омега-Л». 2006. - 382 с. С. 315.
Публичная воля реализуется в нормах права или в правилах, определяющих, в том числе и правосубъектность сторон правоотношения. Индивидуальной воле предшествует интерес субъекта, а следствием её является фактическое правовое поведение, результатом которого становится юридический факт как предпосылка или результат (промежуточный или конечный) развития правоотношения. Таким образом, объективно-волевая компонента выражена в нормах права, с помощью которых осуществляется регулирование общественных отношений и которые рассматриваются в качестве основной предпосылки правоотношения. Субъективно-волевая составляющая определяет правовую активность лиц, их поведение.

Уточним, что для простейшей схемы правоотношения социальная и субъективные воли, по нашему мнению, не охватываются правоотношением, а находятся вне его, поскольку индивидуальная воля реализуется в фактическом поступке (поведении), а публичная воля - в юридической форме правоотношения (правосубъектность сторон, права и обязанности, охватывающие конкретные правила поведения, гарантии прав и обязанностей субъектов и ответственность), по сути, отображающей все аспекты статутно-правового положения сторон и правопорядка. Вместе с тем возможны правоотношения, в ходе развития которых происходит коррекция индивидуальных воль и актов правового поведения.

В связи с вышесказанным, полагаем вполне уместной постановку вопроса о дополнительном исследовании состава известных предпосылок правоотношения на предмет уточнения его полноты и места до него или в нём индивидуальной воли сторон правоотношения.

Возвращаясь к проблеме содержания правоотношения, уточним, что его содержание образуют акты волевого правового (основанного на правовых нормах) поведения участников.

Полагаем, что в определениях правоотношения, а также рассмотренных схемах недостаёт целевой конкретизации правоотношения и требуют уточнения связи. Эта задача решается введением в схему правоотношения как правовой ситуации ещё одного элемента - реализованного субъективного права или защищённого субъективного или публичного права, охватываемых понятием объект правоотношения (объект-результат или объектцель; схема 4), а также следующим уточнением: взаимодействие объективной и субъективных воль, а также взаимовлияние субъективных прав и обязанностей сторон происходит при соверше- 


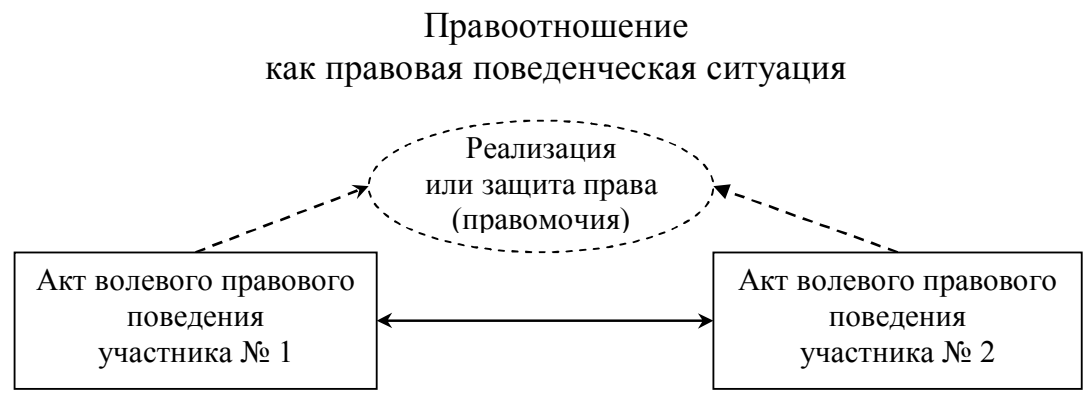

Схема 4 - Содержание правоотношения

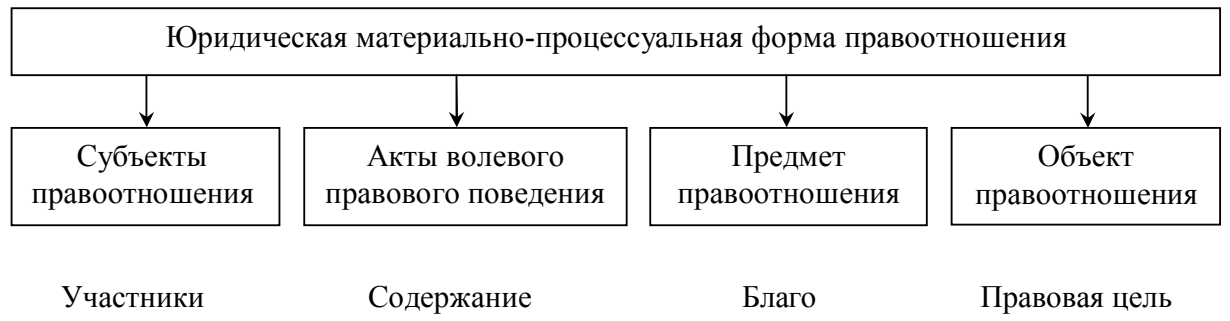

Схема 5 - Общая структура правоотношения

нии актов волевого поведения, характеризуемых с юридических позиций как правовые акты, и имеющих значение правовых связей (поведенческих или материально-правовых).

По нашему мнению правоотношение связано с реализацией субъективного права или защитой субъективно-публичного права или правомочия. Заметим, что такой двойной состав согласуется с представленной C.C. Алексеевым концепцией пассивного и активного типов правоотношения ${ }^{20}$, когда для первого имманентна реализация права, а для второго - защита.

С этих позиций правовая ситуация (правоотношение) характеризуется юридизацией материальной (человек, поведение, благо, правовой результат поведения) и юридически формальной (правовой статус сторон, включающий правосубъектность, права и обязанности, в том числе охватываемые юридической процедурой, их гарантии и ответственность участвующих в правоотношении лиц, а также юридические состояния лиц и предметов) сторон правоотношения и следующим пятиэлементным составом (схема 5).

Подчеркнём, что юридическое значение благ и актов поведения связано с правовым интересом

20 См.: Алексеев С.С. Указ. соч. С. 395-397. и его реализацией, обеспечивающей правовой результат правоотношения в виде, например, нового статуса лица в рамках конституционно-правового, административного, гражданско-правового, трудового, уголовно-правового или международного правоотношения.

Традиции авторских юридических школ обусловили явное «смешение» методологических подходов при исследовании такого юридического феномена как правоотношение. Однако установки на развитие представлений о правоотношении общепризнанны. В частности, С.С. Алексеев, говоря о целостной концепции правоотношения, полагаем, соглашается с приведенным им мнением Р.0. Халфиной ${ }^{21}$, и наиболее существенное значение придаёт, в том числе, следующему обстоятельству: «в правоотношениях юридическая форма и материальное содержание находятся в нераздельном единстве, и, следовательно, проблемы правоотношений необходимо решать с учётом этого фундаментального факта» ${ }^{22}$.

21 «Правоотношение, будучи реализацией нормы, представляет собой вместе с тем и конкретное общественное отношение, облечённое в правовую форму». Там же (со ссылкой на труд Р.О. Халфиной «Общее учение о правоотношении»). С. 335.

22 Там же. С. 344-345. 


\section{Библиография:}

1. Алексеев С.С. Общая теория права: учеб. - 2-е изд., перераб. и доп. - М.: ТК Велби, Изд-во Проспект, $2008 .-576$ с.

2. Иоффе О. С. Правоотношение по советскому гражданскому праву /О. С. Иоффе; Отв. ред. С.И. Аскназий; Ленинградский государственный университет им. А.А. Жданова. Институт экономики, философии и права. - Л.: Изд-во ЛГУ, 1949. - 143 с. URL: http://law.edu.ru/book/book.asp?bookID=13808 (дата обращения - 26.08.2013 г.).

3. Остапюк Н.И. Наследственное правоотношение: понятие и юридическое содержание // Гражданское право, 2006. № 2 .

4. Теория государства и права: Курс лекций / Под ред. Н.И. Матузова и А.В. Малько. - 2-е изд., перераб. и доп. М.: Юристъ, 2001. - 776 с.

5. Толстой Ю.К. К теории правоотношения. - Ленинград: Изд-во Ленинградского Ун-та. - 1959. - 88 с.

6. Халфина Р.О. Общее учение о правоотношении. - М.: Юр. лит. - 1974. - 340 с.

7. Хропанюк В.Н. Теория государства и права. Учебник для высших учебных заведений / Под редакцией профессора В.Г. Стрекозова. - М. Издательство «Интерстиль», «Омега-Л». 2006. - 382 с.

8. Борисов А.М. О проблеме трактовки категории «объект» в правоведении // Актуальные проблемы российского права.-2014.-3.-С. 323-329. DOI: 10.7256/1994-1471.2014.3.9396.

9. Добробаба М.Б. Содержательная характеристика служебно-деликтных правоотношений // Актуальные проблемы российского права.-2013.-11.-C. 1391-1403. DOI: 10.7256/1994-1471.2013.11.8937.

10. Алпатов А.А. Эпистемология и онтология права // NB: Вопросы права и политики. - 2013.-№ 12.-C.127-194. DOI: 10.7256/2305-9699.2013.12.10216. URL: http://e-notabene.ru/lr/article_10216.html

11. Урсул А.Д. Глобальное измерение права // NB: Вопросы права и политики. - 2012.-№ 5.-C.90-146. DOI: 10.7256/2305-9699.2012.5.337. URL: http://e-notabene.ru/lr/article_337.html

12. Чурносов И.М.. Концепция права Рональда Дворкина. // Право и политика.-2014.-№ 4.-C. 529-547. DOI: 10.7256/1811-9018.2014.4.11341

13. Михайлов А.М.. Понятие и функции юридической догматики. // Право и политика.-2014.-№ 3.-C. 387-395. DOI: 10.7256/1811-9018.2014.3.6417

References (transliterated)

1. Alekseev S.S. Obshchaya teoriya prava: ucheb. - 2-e izd., pererab. i dop. - M.: TK Velbi, Izd-vo Prospekt, $2008 .-576$ s.

2. Ioffe O. S. Pravootnoshenie po sovetskomu grazhdanskomu pravu /O. S. Ioffe; Otv. red. S.I. Asknazii; Leningradskii gosudarstvennyi universitet im. A.A. Zhdanova. Institut ekonomiki, filosofii i prava. - L.: Izd-vo LGU, 1949. - 143 s. URL: http://law.edu.ru/book/book.asp?bookID=13808 (data obrashcheniya - 26.08.2013 g.).

3. Ostapyuk N.I. Nasledstvennoe pravootnoshenie: ponyatie i yuridicheskoe soderzhanie // Grazhdanskoe pravo, 2006. № 2.

4. Teoriya gosudarstva i prava: Kurs lektsii / Pod red. N.I. Matuzova i A.V. Mal'ko. - 2-e izd., pererab. i dop. M.: Yurist", 2001. - $776 \mathrm{~s}$.

5. Tolstoi Yu.K. K teorii pravootnosheniya. - Leningrad: Izd-vo Leningradskogo Un-ta. - 1959. - 88 s.

6. Khalfina R.O. Obshchee uchenie o pravootnoshenii. - M.: Yur. lit. - 1974. - 340 s.

7. Khropanyuk V.N. Teoriya gosudarstva i prava. Uchebnik dlya vysshikh uchebnykh zavedenii / Pod redaktsiei professora V.G. Strekozova. - M. Izdatel'stvo «Interstil'», «Omega-L». 2006. - $382 \mathrm{~s}$.

8. Borisov A.M. O probleme traktovki kategorii «ob"ekt» v pravovedenii // Aktual'nye problemy rossiiskogo prava.-2014.3.-C. 323-329. DOI: 10.7256/1994-1471.2014.3.9396.

9. Dobrobaba M.B. Soderzhatel'naya kharakteristika sluzhebno-deliktnykh pravootnoshenii // Aktual'nye problemy rossiiskogo prava.-2013.-11.-C. 1391-1403. DOI: 10.7256/1994-1471.2013.11.8937.

10. Alpatov A.A. Epistemologiya i ontologiya prava // NB: Voprosy prava i politiki. - 2013.-№ 12.-S.127-194. DOI: 10.7256/2305-9699.2013.12.10216. URL: http://e-notabene.ru/lr/article_10216.html

11. Ursul A.D. Global'noe izmerenie prava // NB: Voprosy prava i politiki. - 2012.-№ 5.-S.90-146. DOI: 10.7256/23059699.2012.5.337. URL: http://e-notabene.ru/lr/article_337.html

12. Churnosov I.M.. Kontseptsiya prava Ronal'da Dvorkina. // Pravo i politika.-2014.-№ 4.-C. 529-547. DOI: 10.7256/18119018.2014.4.11341

13. Mikhailov A.M.. Ponyatie i funktsii yuridicheskoi dogmatiki.// Pravo i politika.-2014.-№ 3.-C. 387-395. DOI: 10.7256/18119018.2014.3.6417 